\title{
AN ELABORATION ON THE SYMBOLIC MEANINGS OF NAMES
}

\author{
GRANT W. SMith \\ Eastern Washington University, USA
}

\begin{abstract}
This paper extends my discussion of the symbolic meanings of names from the paper I presented at ICOS 26. In that paper I argue for an understanding of name meaning based on mental associations rather than on grammatical function. This paper will repeat, in briefer form, my review of typical philosophical analyses in order to clarify what I see as their limitations. I wish to argue for a more inclusive and empirical understanding of name meaning, emphasizing their interpretation. Specifically, biological research has recently shown that all words are stored in various areas of the brain along with words of similar relevance to previous experience. Thus, all words, including names, are related to other words as much as they are to the objective phenomena of human experience. The meaning of a word is symbolic insofar as it is found in a contextual relationship rather than in a single referent. Names may therefore be grammatically analyzed as simple indices, but if a name evokes an image recorded in the human brain, it is ineluctably associated with other images giving it a relational meaning and symbolic value. Two surveys will be described here that illustrate the variability of contextual associations in the meanings of names.
\end{abstract}

Keywords: contextual associations, relational vs. causal reference, semiotic, indexical, symbolic.

\section{Introduction}

This paper is an elaboration of my paper for the ICOS meeting in Debrecen the previous week. That paper argues for an understanding of name meaning based on contextual associations and shared interpretations rather than on distinctions between denotation and connotation. Philosophical theories have generally pivoted on such distinctions and on issues of language structure rather than on how language is actually interpreted. As in Debrecen, but here in reduced form, I shall review typical philosophical theories (Mill, Frege, Russell, and Kripke) as a springboard to my own views.

I wish to argue that the meanings of names are not primarily indexical, as most commonly argued, but depend in an essential way on contextual associations that have symbolic values, somewhat as other words do. The associative basis of word meaning has been shown in recent brain research, and this research suggests that the brain tracks the relationships among signs and referents rather than the individual signs and referents themselves. I will offer here at least some evidence of this associative process resulting from two surveys of students responding to well-known place names. I 
hope my discussion of these surveys might stimulate discussion in our many important meetings at and after ICONN4.

\section{Beginning with J. S. Mill}

Looking back, J. S. Mill set the philosophical basis for discussing name meanings in 1843 by drawing a categorical distinction between common and proper nouns. Common nouns carry lexical meaning because their definitions specify sets of common attributes among all items in the class of things named - e.g., the word dog refers to a set of attributes shared by all examples within the class of things we call dogs. Proper nouns, by contrast, such as Fido, do not carry meaning in a categorical sense because they refer to specific rather than common attributes; Mill sees them as indexical designations of individual items within a class.

The weakness of Mill's analysis is that he dismisses contextual associations that might arise in anyone's mind as a part of meaning. Such associations are, according to Mill, incidental to the act of reference rather than vital to it: "By saying: This is York, [the listener may understand] that it contains a Minster. But this [is] by virtue of what he has previously heard concerning York, not by anything implied in the name" (Mill [1843] 1973: 36). But to what does a name refer?

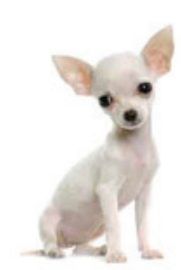

Fido 1

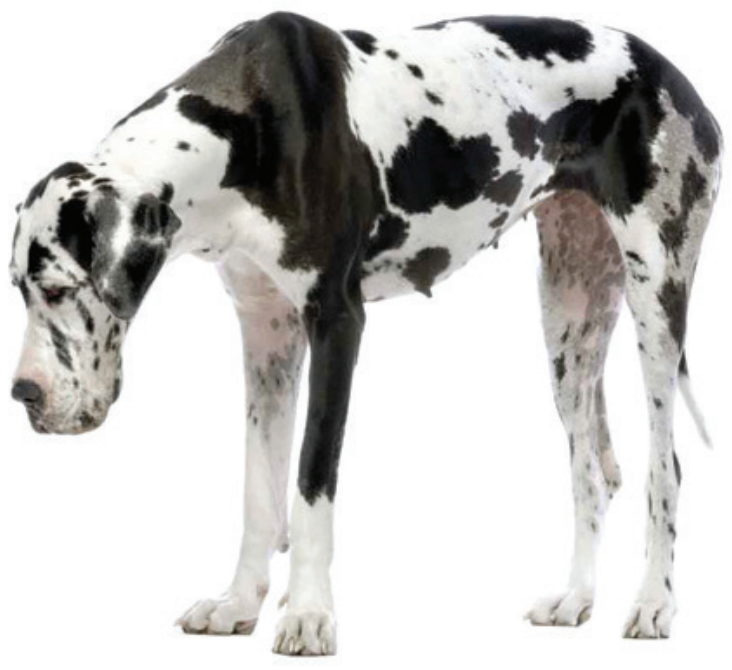

Fido 2

Figure 1

Mill's dismissal of contextual associations ignores interpretive processes that are in fact necessary for the recognition of a referent and for distinguishing between different referents similarly named. The name Fido can evoke no meaningful reference, 
indexical or otherwise, without also evoking pre-existing images in the human mind, i.e., contextual associations.

\section{Descriptive theories of meaning}

Since Mill's time, philosophical theories of name meaning have become described as descriptive or causal. The descriptive theories argue that names carry a special type of meaning because of the context in which they are found (Frege) or because of their propositional status within the real world (Russell).

Frege noted that two names for the same referent may carry what he called different senses. Using the name Mark Twain, for example, is not the same as using Samuel Clemens (Frege 1970: 58). Frege concludes that names clearly denote individual things apart from classes of things, a linguistic function that he calls their reference, but names also carry connotations (derived from contextual associations), which he calls their sense.

Thus, Frege recognizes both denotation and connotation as separate functions of a name, but he denies the importance of subjective differences (Frege 1970: 61). The sense of a word, according to Frege, has significance only insofar as its context is verifiable within a linguistic community.

In denying the significance of subjective interpretation Frege places strict emphasis on the logical structure of language per se (i.e., the linguistic functions of names) and neglects the imperfect sharing of contextual associations between addressers and addressees, upon which human communication depends. I believe that language, reference, and meaning depend on partially shared contextual associations and on personal associations that prompt recognition.

Russell rejected Frege's distinction between sense and reference in order to place even more emphasis on logical analysis. He theorized that names are, in fact, abbreviated forms of logical propositions. The statements, "The present King of France is bald," and "The present King of France is not bald," are both false because the reference is false. That is to say, the reference, "the present King of France," is an abbreviation of the proposition, "This man is the present King of France," and such a proposition is obviously false. There is no man, either bald or not bald, who might be described as the "present King of France."

Russell thereby claims that names "have no meaning in isolation" (1905: 118) but take on definite descriptive meanings from appropriate contexts within a knowable world that is subject to logical analysis. Their meanings are not subject to personal interpretations but need to be judged true or false, depending on the context in which the names have propositional status.

Russell is happy to point out that denials of false propositions are true, such as, "Santa Claus is not a real person." At the same time, two referents with the same name may be both true, but Russell does not explain how two such referents are distinguished by the addresser or addressee (see Jakobson 1960: 350-377). 


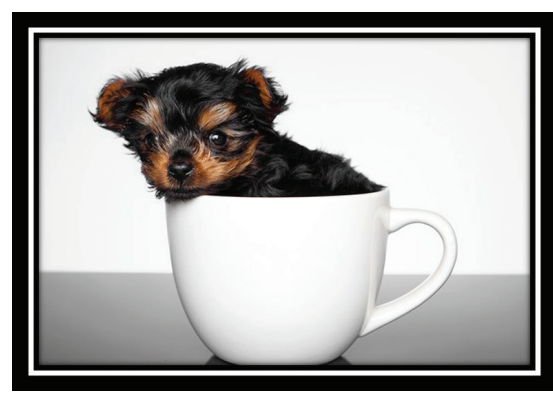

Fido 1

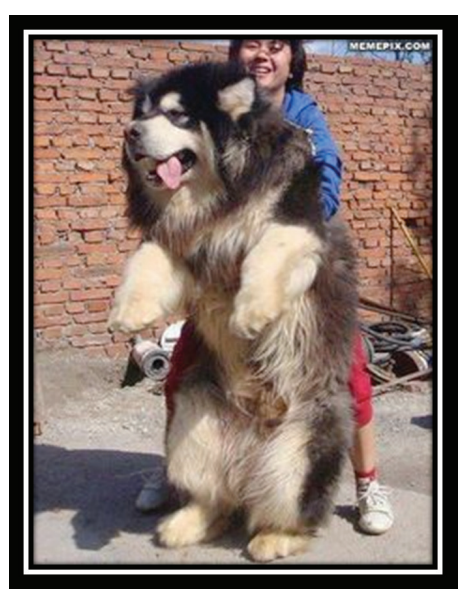

Fido 2

Figure 2

These descriptive theories of names clearly assert the contextual basis of meaning, but as logical analyses, they focus narrowly on the structure of language as a fixed construct in a knowable world. They emphatically exclude variations of interpretations among the users of the names and the potential range of associations that may be evoked in the minds of different people. But is one Fido any less real than another?

\section{Causal theories of meaning}

Causal theories stem from S. Kripke's lectures at Princeton University in 1970 and published a little later as Naming and Necessity. Kripke argues that we need not be acquainted with a uniquely identifying description of an entity, as posited by Russell, in order to use a name correctly. One only needs to use a name in a way that correctly identifies the entity in question, and in order to do so, one's use of a name need only be a link in a chain of uses following the cause of the name (i.e., the initial dubbing). The meanings of names (and even natural kinds, such as gold and water) are, in Kripke's view (and that of other causal theorists, e.g., F. Kroon), fundamentally indexical.

\section{Some empirical observations}

Philosophical analysis helps to clarify logical categories, but causal observation will detect little logic in how the human brain actually processes language. Recent research has shown that the brain processes all words in varied patterns depending on where they are stored in the brain. As a type of word, names exist in the brains of potential interpreters alongside many other words linked to images imprinted there from previous experience and reinforced by conversations, reading, various media, and mental play.

Using MRIs and charting blood flow, scientists have found that word recognition 
is distributed in clusters across the cerebral cortex and in many different areas that span both hemispheres of the brain (Huth, et. al. 2016). Furthermore, the clusters represent types of meaning. For example, words associated with people are generally clustered in certain areas, words associated with places are also clustered together, and the types of clustering vary from person to person.

Our interpretations of words are therefore colored by nearby words and images in the same brain area, the types of coloring vary from person to person, and the clusters vary over time because of additional experiences producing different types of reinforcement.

\section{The associative context}

J. S. Mill was correct in noting the importance of denotation. Names are used to identify individual entities, be they conceptual or physical, but Mill was wrong to dismiss the associations that actually enable an addressee to locate the referent within a mental universe of words and experiences.

For some addressees the reference of the word York is located in the brain only if it has an association with a "minster." There are many Yorks, and a communication cannot succeed unless the addresser and the addressee share some, but not necessarily all, of the same associations that can be evoked by the word. Similarly, many here or around the world would have no idea what I might refer to as Spokane without my supplying some context, doing my best, of course, to use poetic images.

Furthermore, whatever context I supply will be incomplete, limited to a selection of my own associations, and only partially recorded and stored in the brain of any addressee. At the same time, a name that evokes multiple associations will suggest a relationship of qualities shared by those associations, and insofar as the qualities are shared, the meaning is relational and symbolic - rather than merely indexical, or just a link in a causal chain.

\section{A description of procedures for two surveys}

To illustrate the ways in which people recognize the referent of a name with different contextual associations, I asked students in two of my classes to respond to nearby place names in two separate surveys. In one survey 79 students were asked to state what comes to mind with the word Spokane. Spokane is the name of the nearby city (pop. 210,000) where most students work and live and with which they are very familiar. Responders generally assumed the location of the city and proceeded to identify the referent with contextual associations.

In a second survey 28 students were asked to state what comes to mind with the word Vancouver, the name for two cities, each about $500 \mathrm{~km}$ away from our university, and about $500 \mathrm{~km}$ apart from one another. The larger one (pop. 631,500) is just north of the border in Canada, and the other (pop. 161,800) is to the south across the Columbia River from Portland, Oregon.

Again, the responders identified one city or both with widely differing associations. Ten responders (35.7\%) focused exclusively on the city in Canada, seven 
(25.0\%) exclusively on the U.S. city to the south, six (21.4\%) gave no indication of which referent, and five (17.9\%) clearly indicated the two possible referents.

\section{Summary of results}

Responders usually mentioned several associated images by which they identified the referent. 79 responses to the word Spokane resulted in a total of 193 contextual associations, and 28 responses to Vancouver resulted in 73 contextual associations. For the purpose of analysis, I have sorted these associated images in two ways, 1) levels of specificity, and 2) thematic categories.

8.1. Three levels of specificity (The number of associated images follow in brackets.)

1) Named things, such as specific events ("Hoopfest"), parks ("Riverfront Park"), personalities ("Bing Crosby"), personal experience ("my Chlamydia”) or athletic teams ("Canucks"). [Spokane, 65; Vancouver, 36]

2) Common occurrences or activities, such as "volleyball tournaments," "rainy days," "party hotspot," "family/friends," and "peach cider;" [Spokane, 74; Vancouver, 27]

3) General evaluations, such as "kinda gloomy," "bad areas," "politically conservative," "beautiful places," "good food," and "outspoken street art." [Spokane, 54; Vancouver, 10] brackets.)

8.2. Nine thematic categories (Again, the number of associated images follow in

1) Natural features (including weather), such as "lilacs," "the water falls," "basalt rock," "beautiful sunsets," "Ponderosa pines," "snow-capped mountains," and "the ocean." [Spokane, 35; Vancouver, 19]

2) Cultural features, such as "Riverpark Square," "clock tower," "Palisades Park," "Davenport Hotel," "the dam," and "outlying suburbs." [Spokane, 32; Vancouver, 9]

3) Geographic location, such as "Inland Northwest," "right on the border," "Canada," and "western Washington." [Spokane, 1; Vancouver, 19]

4) Public events, especially sports, such as "Expo 74," "Bloomsday," "Hoopfest," "Gonzaga basketball," "the Chiefs," "the Canucks," and "the Spokane Indians (baseball)." [Spokane, 20; Vancouver, 9]

5) Kinship/friendship, such as "home," "my family," "where I grew up," "my exgirlfriend," and "my friends who live there." [Spokane, 30; Vancouver, 5]

6) Food, such as "coffee," "bacon," "maple syrup," and "peach cider." [Spokane, 3; Vancouver, 4]

7) Types of people, such as "Native Americans," "Russians," "homeless people," "welcoming people," "old people," "interesting people," and "Eh?" [Spokane, 25; Vancouver, 1]

8) Personal experience, such as "purse stolen at Wendy's," "my Chlamydia," 
"where the drinking age is 19," "lots of potholes," "traffic," and "wonderful fishing." [Spokane, 26; Vancouver, 5]

9) Politics/popular culture, such as "museums," "books," "Zac Brown Band," "graffiti," "boring," "Rachel Dolezal," "liberal morons," "Bing Crosby," "marijuana," "Republicans," "Milee Meyers," and "a filming place for Supernatural." [Spokane, 21; Vancouver, 2]

\section{Discussion}

These results show that the responders thought of the referents symbolically, insofar as the types of references may be defined in semiotic terms. That is to say, their identifications of the immediate referents depended on associated images and assumed that the immediate referents share a limited number of qualities evoked by the associated images, as illustrated in the following diagram.

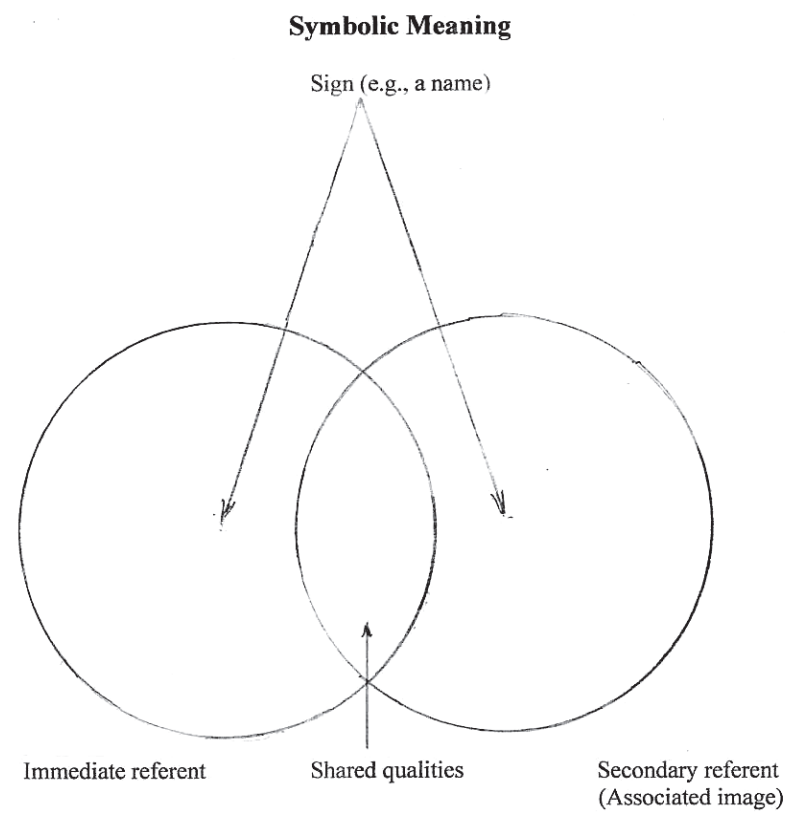

Figure 3

These associated images may be viewed as secondary referents from which meaning is partially transferred to, and shared with, the immediate referent, much as meaning is partially transferred between the vehicle of a metaphor and its tenor (see M. Black 1962: 38-46).

Of course, words functioning as signs often come together as sentences, and so a diagram should look more like this: 


\section{A Diagram of Symbolic Discourse}

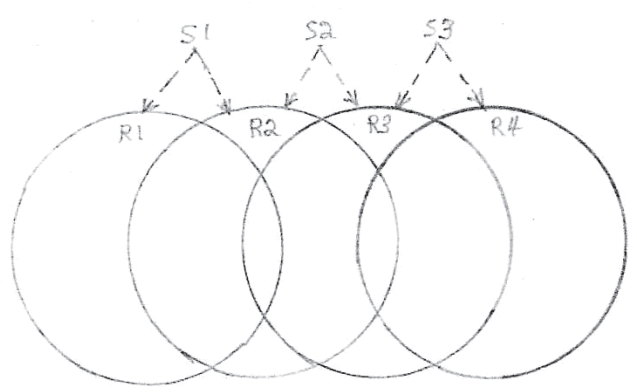

Figure 4

The hypothetical signs, S1, S2, and S3, refer to two or more hypothetical referents. The circles represent a variable range of attributes of the referents R1, R2, R3, and $\mathrm{R} 4$. The referents are thereby understood in terms of one another, and the meaning is relational, i.e., symbolic, rather than causal.

The symbolic sharing of meaning is especially clear in the specificity of the associated images. The 79 responders identified Spokane by citing 63 very specific images, and 28 responders identified Vancouver with 36 such images. This level of specificity emphasizes the partiality of shared qualities, not the actual equivalence of the immediate and secondary referents (nor, of course, any equivalence of the sign and its referents).

Thus, the meaning of each name is recognized as the qualities shared within a set of pre-existing associated images, and so the meaning is relational and symbolic. It is not seen as a mere designation of physical attributes on a causal chain. It may also correlate very little, or not at all, with reality, as we can see with such words as unicorn, griffin, and vampire. The human mind revels with symbolic references, especially in our fantasies, and language is essentially symbolic insofar as it implies a system of ordered relationships "among the infinite array of possible indexical references" (Smith 2006: 14). This complexity is heightened, according to Peirce, by the fact that signs may be interpreted iconically, indexically, and symbolically at the same time.

In these surveys, the general failure of responders to distinguish between the two cities named Vancouver shows the mental focus of the responders to have been on specific images. Also, the qualities by which the particular city is recognized lie in the specific images, and without these or other specific images, the city is not distinguishable or recognizable.

The symbolic meanings of the names are also shown by the variation of the responses. Nineteen of the responders referred to Spokane with the words "home" or "hometown." Such a number seems high in absolute terms but is low (barely 24\%) in view of the fact that most responders live in Spokane (75\%), and the phrasing is not 
highly specific. Among the 65 highly specific secondary references, the most frequent reference (the annual Bloomsday Run) was five ( $7.7 \%$ in this category and $2.6 \%$ overall).

The images associated with Vancouver were equally or more diverse. Only one thought of this name as "home," three referred to "the hockey team" or "the Canucks," three referred to a scenic dam near the Canadian city, and four referred to "rain," proverbial in both cities compared to Spokane. The diversity of the highly specific images shows that the responders understood the names in different qualitative (hence symbolic) terms - e.g., "politically conservative" vs. "liberal morons" for Spokane.

\section{Conclusions}

If the two immediate referents, Spokane and Vancouver, had been understood merely as one-to-one designations, much greater uniformity should have been found among the responses of these surveys. Instead, they show these names to be understood because of pre-existing images partially associated with the names. The partial sharing of qualities makes the cognitive act relational (not part of a causal chain) and therefore symbolic.

The variation of the responses also show that the understanding of these place names is subjective and generally rooted in personal experience, as in "my Chlamydia" and "wonderful fishing." The names did not evoke any type of common meaning (or "sense," as Frege would have it) from a verifiable context, nor suggest an abbreviated proposition (as Russell would have it). Instead they evoked a variety of images imprinted on nearby areas of the brain by previous experience of the different responders.

Of course, personal experience is conditioned and reinforced by culture, and there is enough uniformity in these responses to suggest that respondents thought of the names as designating something. As noted above, Peirce emphasized that the meaning of a sign often functions as an icon, index, and symbol at the same time. Thus, we should assume that the respondents to these surveys thought of the names as designations but that their understandings of the names were symbolic at the same time. The names are understood only in a context of associated images that vary from person to person and, of course, over time.

The associated images are in fact the basis of name coinage. When trappers first came to the river falls now in the middle of downtown Spokane, they were met by the leader of the local Indians. This leader pointed to himself and said, "illim spulkani," which meant, approximately, "child of the rainbow," referring to the refracted sunlight from the spray of the waterfall where he lived.

The trappers interpreted his two words as his given and family names and decided to name their encampment in honor of him, Spokanee, just as the founders of the other two cities honored Captain George Vancouver who had charted those waters in 1792.

Understanding a name, or any word, requires contextual associations, and our choices of names for official maps require some agreement about which of those associations seem most appropriate. Our task as onomasts is to sort through those associations and find the meanings commonly used. 


\section{References}

Black, M. 1962. Models and Metaphors: Studies in Language and Philosophy. Ithaca, NY: Cornell University Press.

Frege, F. L. G. 1970. Über Sinn und Bedeutung. In Zeitschrift für Philosophie und philosophische Kritik. 100: 25-50. Translated as "On Sense and Reference" by M. Black in Translations from the Philosophical Writings of Gottlob Frege, second edition, P. Geach and M. Black (eds. and trans.), 56-78. Oxford: Blackwell.

Huth, A. G., et. al. 2016. Natural Speech Reveals the Semantic Maps that Tile Human Cerebral Cortex. Nature 532 (April 27): 453-458.

Jakobson, R. 1960. Closing Statements: Linguistics and Poetics. In Style in Language, T. A. Sebeok (ed.), 350-377. Cambridge Massachusetts: MIT Press.

Kripke, S. 1980. Naming and Necessity. Cambridge, MA: Harvard University Press.

Kroon, F. 2004. Descriptivism, Pretense, and the Frege-Russell Problems. The Philosophical Review 113: 1-30.

Mill, J. S. 1973. A System of Logic. In Collected Works of John Stuart Mill, Vol. VII, J.M. Robson (ed.). Toronto: University of Toronto Press.

Peirce, C. S. 1955. Logic as Semiotic: The Theory of Signs. In The Philosophical Writings of Peirce, J. Buchler (ed.), 98-119. New York: Dover Books.

Russell, B. 1973. On Denoting. Mind 14: 479-493. In Essays in Analysis, D. Lackey (ed.), 103119. New York: George Braziller.

Smith, G. 2006. A Semiotic Theory of Names. Onoma 41: 14-26. 